\title{
EVALUATION OF ANTIOXIDANT, ANTIMICROBIAL, AND ANTIFUNGAL POTENTIAL OF CUCURBITA PEPO VAR. FASTIGATA SEED EXTRACTS
}

\author{
ROSHNI RS SONI ${ }^{1 *}$, MANOJ BALI ${ }^{2}$ \\ ${ }^{1}$ Department of Applied Sciences, Quest Group of Institutions, Jhanjeri, IKG-Punjab Technical University, SAS Nagar, Punjab, India. \\ ${ }^{2}$ Baba Hira Singh Bhattal Institute of Engineering and Technology, Lehragaga, IKG-Punjab Technical University, Sangrur, Punjab, India \\ Email: roshimanjot@gmail.com
}

Received: 20 April 2018, Revised and Accepted: 27 October 2018

\begin{abstract}
Objective: The current study aims to study the antioxidant and antimicrobial and antifungal potential of the methanolic extract of $C$ ucurbita pepo var. fastigata seeds (MECS).

Methods: Extraction of the seeds has been carried out with solvents of increasing polarity (chloroform, acetone, and methanol) and the phytochemical study of the methanolic extract have been carried out using standard methods. The free radical scavenging activity of all the extracts was evaluated by DPPH and $\mathrm{H}_{2} \mathrm{O}_{2}$ methods. Standard disk diffusion method was used to evaluate antibacterial and antifungal activities.

Results: Phytochemical evaluation showed the maximum presence of triterpenoids, phenolic compounds, tannins and small amount of Coumarins. Methanolic extract revealed momentous antioxidant activity as compared to chloroform and ethyl acetate extract. Hence, methanolic extract of C. pepo. seeds (MECS) at a dose level of 100, 200 and $300 \mu \mathrm{g} / \mathrm{ml}$ was evaluated for antioxidant potential. Maximum free radical scavenging activity of methanolic seed extract of cucurbita pepo var. fastigata has been found at a dose of $300 \mu \mathrm{g} / \mathrm{ml}$ to be $63 \pm 0.16 \%$ by 1,1 -diphenyl-2-picryl hydrazyl model and at a value of $78 \%$ at $300 \mu \mathrm{g} / \mathrm{ml}$ with $\mathrm{H} 202$ model. Methanolic extract also showed the presence of antibacterial activity.
\end{abstract}

Conclusion: Presence of phytochemicals in the methanolic extract is responsible for the antioxidant potential. Extracts were investigated for antibacterial activity using the standard disc diffusion assay method against Bacillus subtilis, Escherichia coli, Staphylococcus aureus, and Pseudomonas aeruginosa and for the antifungal activities against Aspergillus niger and Candida albicans. The seed extract showed the presence of antibacterial activity, but the antifungal activity was found to be absent in the extract.

Keywords: Antimicrobial, Antioxidant, Cucurbita pepo var. fastigata, Free radical scavenging.

(c) 2019 The Authors. Published by Innovare Academic Sciences Pvt Ltd. This is an open access article under the CC BY license (http://creativecommons. org/licenses/by/4. 0/) DOI: http://dx.doi.org/10.22159/ajpcr.2019.v12i2.28040

\section{INTRODUCTION}

According to the WHO, medicinal plants as therapeutic aids have momentous role in curing and maintaining appropriate health [1-3]. Nature has been practicing combinational chemistry for eons [4] and numerous natural products and synthetically modified natural product have been developed for treatment [5]. The structural analysis and the ability to amalgamate them permitted chemists to amend them to repress or enhance their solubility and efficiency [6]. The ethanolic and aqueous extract of Cassia fistula Linn. shows the presence of various antioxidants such as kaempferol, gallic acid, ellagic acid, coumaric acid, rutin, myricetin, and quercetin [7].

The Cucurbita pepo var. fastigata belongs to the Cucurbitaceae family which consists of 130 genera and 800 species. Some of the important plants are Momordica charantia, C. pepo, Cucurbita andreana, Cucurbita ficifolia, Cucumis sativus, Cucumis melo, Citrullus colocynthis, Luffa echinata, Trichosanthes kirilowii, Lagenaria siceraria, and Benincasa hispida [8]. Literature reveals the traditional use of the various parts of the plant by Ayurvedic \& Chinese systems as anti-inflammatory, analgesic, antidiabatic, antiulcer, and antioxidant. The fruit is used to cure fatigue \& thirst, acts as a blood purifier, treats cold. The seeds are diuretic, helpful in headaches neuralgia, bronchitis, fever, Gastritis, burns, febrile diseases, irritable bladder \& prostatic complains. The seeds are also beneficial to spleen, lungs and act as taenicide. The leaves are used for the treatment of nausea \& helps to boost haemoglobin [9]. Oil obtained from C. pepo. seeds is recommended in nutritional and medicinal purpose as it acts as a potential drug able to heal wounds in animal [10]. C. pepo is chiefly known for its enhancement in prostatic hyperplasia (benign prostatic hyperplasia) [11], urinary dysfunction, and cytotoxic properties and also has also been used widely as a hypoglycemic agent. Many pharmacological studies have established hepatoprotection, restrain benign prostatic hyperplasia, antioxidant, anticancer, anti-inflammatory, antidiabetic, and antiulcer activities supporting its customary uses $[9,12]$. The seeds, in addition to their roles as food additives and supplements, may also be used as an efficient and economical source of antibacterial agents for the treatment of bacterial infections [13]. The methanolic, chloroform, and ethyl acetate extracts of $C$. pepo fruits significantly reduced the paw swelling in mice dose dependently suggesting the immunomodulatory effects of extracts and can, therefore, act as immunonutrient $[14,15]$. The natural plant components found in pumpkin could recover the liver against alcoholinduced liver toxicity and oxidative stress in rats [16]. The cell growth inhibition of prostate, breast, and colon cancer cells by ethanolic seed extract authenticates the ethnomedical use of pumpkin seeds for a treatment of benign prostate hyperplasia [17].

The adequate ROS \& RNS is vital for the efficient immune response as the imbalance between the production of oxidants/RONS and their removal by antioxidants lead to increased accumulation and, hence, the condition of oxidative stress [18]. Oxidative stress has been recognized as the major reason of the development and progression of numerous ailments. Supplements rich in exogenous antioxidants or boosting endogenous antioxidant defenses of the body are a capable way of skirmishing the unwanted effects of ROS-induced oxidative damage. Plants have an innate ability to biosynthesize a wide range of nonenzymatic antioxidants capable of attenuating ROS-induced oxidative damage [19]. Antioxidant defense system plays a key role to overcome 
different diseases caused as a result of free radicals by neutralizing the excess of free radicals. An antioxidant is a molecule stable enough to donate an electron to a rampaging free radical and neutralize it, thus reducing its capacity to damage. These antioxidants delay or inhibit cellular damage mainly through their free radical scavenging property [20]. However antioxidant, antimicrobial and antifungal studies have not yet been reported for the seeds of Cucurbita pepo var. fastigata extract. So the present study has been carried out to evaluate the antifungal, antimicrobial and antioxidant potential of Cucurbita pepo var. fastigata seeds.

\section{METHODS}

Chemicals

1,1-diphenyl-2-picrylhydrazyl (DPPH) and hydrogen peroxide were procured from Hi-Media. Carrageenan and ascorbic were obtained from Jackson Laboratories, Amritsar, Punjab. The solvents such as hexane, chloroform, ethyl acetate, and methanol were of analytical grade and procured from SD Fine Chemical.

\section{Plant material}

The seeds of $C$. pepo var. fastigata were bought from Local Market of Kharar (PB)/Roopnagar (PB)/Chandigarh (UT) and Delhi, 2013. The seeds were authenticated by Prof. Satwinderjeet Kaur and the letter vide ref no: 0176 has been deposited in the Botanical and Environmental Science Department, Guru Nanak Dev University, Amritsar. The seeds were cleaned, washed, dried for 2 days, and crudely powdered in a grinder at room temperature. The sample was kept in light-protected air-tightened containers.

\section{Extraction}

The powdered seed material was subjected to defatting i.e., removal of fats using hexane, and then, extraction was carried out using solvents of increasing polarity such as chloroform, acetone, and methanol by cold maceration process for $24 \mathrm{~h}$. The solvents were completely removed by rotary evaporator and crude extracts were obtained and stored in the refrigerator. These extracts were further used for evaluation of their antioxidant, antibacterial, and antifungal activities.

\section{Phytochemical screening}

Standard procedures for preliminary phytochemical screenings of the extracts were carried out to analyze the presence of various constituents. The extracts obtained were analyzed for flavonoids, tannins, alkaloids,

Table 1: Phytochemical screening of $C$. pepo var. fastigata seeds extracts/isolated comp

\begin{tabular}{ll}
\hline Plant constituent/test & C. pepo var. fastigata \\
\hline Alkaloids & - \\
Carbohydrates & - \\
Phytosterols & - \\
Phenolic compounds and tannins & ++ \\
Triterpenoids & +++ \\
Flavonoids & - \\
Coumarins & + \\
\hline
\end{tabular}

C. pepo: Cucurbita pepo

Table 2: DPPH scavenging activity by metabolic seed extract of Cucurbita pepo var, fastigata.

\begin{tabular}{llc}
\hline $\begin{array}{l}\text { Concentration } \\
(\mu \mathrm{g} / \mathrm{ml})\end{array}$ & \multicolumn{2}{c}{$\%$ age scavenging } \\
\cline { 2 - 3 } & $\begin{array}{l}\text { Methanol } \\
\text { extract }\end{array}$ & Ascorbic acid \\
\hline 100 & $45.73 \pm 0.27$ & $50.23 \pm 0.49$ \\
200 & $58.72 \pm 0.45$ & $64.74 \pm 0.58$ \\
300 & $76.35 \pm 0.52$ & $82.88 \pm 0.87$ \\
\hline
\end{tabular}

Values are the average of triplicate experiments and represented as mean \pm standard error of the mean. DPPH: 1,1-diphenyl-2-picrylhydrazyl triterpenes, sterols, protein, carbohydrates, and amino acids. The identification was done on the basis of color change for the respective components $[21,22]$. Further, seclusion and characterization of pure compounds from the extract are in progress.

\section{Antioxidant activity}

Qualitative scavenging activity on DPPH radical

The qualitative assays were accomplished according to simple screening method for antioxidants [23]. Dilution of $2 \mathrm{mg}$ of each extract was done with $1 \mathrm{ml}$ of the suitable solvent, following which a small quantity of each dilution was cautiously laden onto the baseline of the $20 \mathrm{~cm}$ by $10 \mathrm{~cm}$ TLC plates, and the sample was allowed to dry for some time. Hexane-ethyl acetate in ratio of 7:3 was used as the mobile phase. The dried plates were sprayed with a $0.2 \%$ solution of DPPH in ethanol. The extracts having antioxidant constituent displayed a yellow on purple spot due to the discoloration of DPPH [24].

\section{Quantitative scavenging activity on DPPH radical}

Antioxidant potential of methanolic seed extract of C. pepo. var. fastigata was evaluated by 1,1-diphenyl-2-picryl hydrazyl radical scavenging activity. The reduction capability of 1, 1-diphenyl-2-picryl hydrazyl radical was determined by the decrease in its absorbance at $517 \mathrm{~nm}$. DPPH radical is scavenged by antioxidants through the donation of a proton, which forms the reduced DPPH and lead to decrease in absorbance at a wavelength of $517 \mathrm{~nm}$ [25] . Ascorbic acid was used as standard and blank was used to remove the influence of the color of the samples. A methanolic solution of DPPH was used as negative control.

Table 3: Antioxidant activity of metabolic seed extract of Cucurbita pepo var. fastigata by hydrogen peroxide method

\begin{tabular}{lllll}
\hline $\begin{array}{l}\text { Concentration } \\
(\boldsymbol{\mu g} / \mathbf{m l})\end{array}$ & $\begin{array}{l}\text { Absorbance } \\
(\mathbf{n m})\end{array}$ & Mean & & \multicolumn{2}{l}{ \% age scavenging } \\
\cline { 3 - 5 } & & & $\begin{array}{l}\text { Methanol } \\
\text { extract }\end{array}$ & $\begin{array}{l}\text { Ascorbic } \\
\text { acid }\end{array}$ \\
\hline 100 & 0.273 & 0.274 & $20.17 \pm 0.27$ & $44.43 \pm 0.26$ \\
& 0.275 & & & \\
& 0.276 & & & \\
200 & 0.205 & 0.210 & $40.05 \pm 0.11$ & $55.03 \pm 0.46$ \\
& 0.210 & & & \\
300 & 0.215 & & & \\
& 0.102 & 0.106 & $70.17 \pm 0.14$ & $72.17 \pm 0.32$ \\
& 0.110 & & & \\
& 0.106 & & & \\
\hline
\end{tabular}

Values are the average of triplicate experiments and represented as mean \pm standard error of the mean

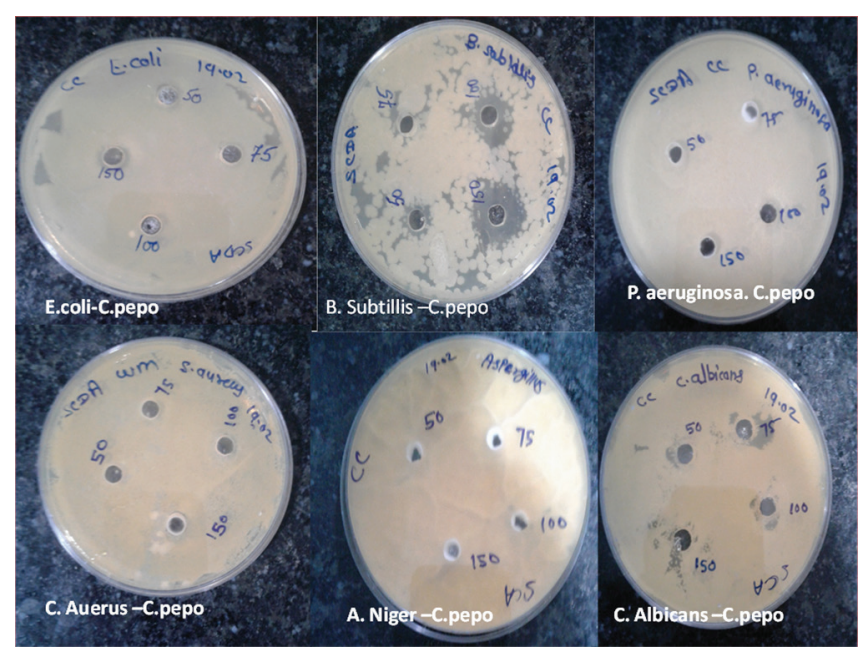

Fig. 1: Inhibition of bacterial growth of the methanolic extract of Cucurbita pepo. seeds by disc diffusion method 
Table 4: Antibacterial activity of methanolic seed extract of Cucurbita pepo var. fastigata by disk diffusion method

\begin{tabular}{|c|c|c|c|c|c|c|}
\hline \multirow[t]{2}{*}{ S. No } & \multirow[t]{2}{*}{ Component } & \multirow[t]{2}{*}{ Concentration $(\mu \mathrm{g} / \mathrm{ml})$} & \multicolumn{4}{|c|}{ Zone of inhibition for bacteria } \\
\hline & & & B. subtilis & E. coli & S. aureus & P. aeruginosa \\
\hline \multirow[t]{4}{*}{1} & C. pepo var. fastigata & 50 & Resistance & Resistance & Resistance & Resistance \\
\hline & & 75 & $14 \mathrm{~mm}$ & Resistance & $13 \mathrm{~mm}$ & Resistance \\
\hline & & 100 & $16 \mathrm{~mm}$ & Resistance & $14 \mathrm{~mm}$ & Resistance \\
\hline & & 150 & $19 \mathrm{~mm}$ & Resistance & $15 \mathrm{~mm}$ & Resistance \\
\hline
\end{tabular}

B. subtilis: Bacillus subtilis, E. coli: Escherichia coli, S. aureus: Staphylococcus aureus, P. aeruginosa: Pseudomonas aeruginosa

Table 5: Antifungal activity of methanolic seed extract of Cucurbita pepo var. fastigata by disk diffusion method

\begin{tabular}{lllll}
\hline S. No & Component & $\begin{array}{l}\text { Concentration } \\
(\boldsymbol{\mu g} / \mathbf{m l})\end{array}$ & $\begin{array}{l}\text { Zone of inhibition for } \\
\text { fungus }\end{array}$ & \\
\cline { 3 - 5 } & & A. niger & C. albicans \\
\hline 1 & C. pepo var. & 50 & Resistance & Resistance \\
& fastigata & 75 & Resistance & Resistance \\
& 100 & 150 & Resistance & Resistance \\
& & Resistance & Resistance \\
\hline
\end{tabular}

A. niger: Aspergillus niger, C. albicans: Candida albicans

Tests were carried out in triplicate. Percentage inhibition was evaluated by using the equation 1 .

I (\%) $=\left(\mathrm{A}_{0}-\mathrm{A}_{\mathrm{s}}\right) / \mathrm{A}_{0} \times 100$

Where, $A_{0}=$ values for the absorbance of the negative control.

$\mathrm{A}_{\mathrm{s}}=$ The absorbance of the sample [26].

Free radical scavenging activity of metabolic seed extract by hydrogen peroxide method

Hydroxyl radical formation can occur in several ways by far the most important mechanism in vitro is the Fenton reaction where a transition metal involved as a prooxidant in the catalyzed decomposition of superoxide and hydrogen peroxide [27]. Hydroxyl radicals are the most reactive and predominant radical generated endogenously during aerobic metabolism among the ROS which could be formed from superoxide anion and hydrogen peroxide, in the metal ions, such as copper or iron and causing some diseases and ageing as well $[28,29]$. The hydroxyl radical is an extremely reactive free radical formed in biological systems and has been implicated as a highly damaging species in free radical pathology, capable of damaging almost every molecule found in living cells [30]. In the present study, the seed extract was evaluated for their hydroxyl radical scavenging activity.

\section{Antibacterial activity}

Extracted dilution was prepared in $50 \mu \mathrm{L}, 75 \mu \mathrm{L}, 100 \mu \mathrm{L}$, and $150 \mu \mathrm{L}$ [31]. Required glassware was washed and dried in a hot air oven. The sterilized agar medium was transferred into the Petri dishes and was allowed to solidify at room temperature. The selected test organism (bacterial) was spread over the solidified agar with the help of a swab stick. Sterile borer was used to make wells of $8 \mathrm{~mm}$ diameter. The dilutions of Extracted sample $(50 \mu \mathrm{l}, 75 \mu \mathrm{l}, 100 \mu \mathrm{l}, 150 \mu \mathrm{l})$ were done in the wells with the help of a sterile syringe needle. The Petri plates were placed in a refrigerator for $5 \mathrm{~min}$ to allow diffusion. Later, the Petri plates were incubated in inverted position at $37^{\circ} \mathrm{C}$ for $24 \mathrm{~h}$ in the incubator. After $24 \mathrm{~h}$, the zone of inhibition was observed and diameter in $\mathrm{mm}$ was measured and recorded.

\section{RESULTS AND DISCUSSION}

\section{Phytochemical screening}

Phytochemical evaluation revealed that the methanolic extract of Cucurbita pepo. var. fastigata seeds showed maximum presence of triterpenoids, phenolic compounds, tannins and small amount of
Coumarins (Table 1), due to which it was further subjected to in vitro antioxidant studies. Polyphenolic compounds, triterpenoid and steroid found in plants, have been reported to have multiple biological effects including antioxidant activity [32-35].

\section{Qualitative DPPH radical scavenging activity}

DPPH method was used to estimate the antioxidant activity of the C. pepo. seed's extracts. The qualitative DPPH radical scavenging activity was demonstrated due to change in the coloration from purple to yellow on the TLC plate by the extract.

\section{Quantitative DPPH radical scavenging activity}

In quantitative estimation, DPPH radical was used as a substrate to evaluate the free radical scavenging activity of the methanolic extract of C. pepo var. fastigata was shown at a dose of $300 \mu \mathrm{g} / \mathrm{ml}$ is $63 \pm 0.16 \%$ by 1,1-diphenyl-2-picryl hydrazyl model as shown in Table 2.

Free radical scavenging activity of metabolic seed extract by hydrogen peroxide method

Hydroxyl radical formation can occur in several ways by far the most important mechanism in vitro is the Fenton reaction where a transition metal involved as a prooxidant in the catalyzed decomposition of superoxide and hydrogen peroxide [27]. Hydroxyl radicals are the most reactive and predominant radical generated endogenously during aerobic metabolism among the ROS which could be formed from superoxide anion and hydrogen peroxide, in the metal ions, such as copper or iron and cause aging of human and some diseases $[28,36]$. The hydroxyl radical is an extremely reactive free radical formed in biological systems and has been implicated as a highly damaging species in free radical pathology, capable of damaging almost every molecule found in living cells [30]. In the present study, the seed extract was evaluated for their hydroxyl radical scavenging activity. Maximum free radical scavenging activity of methanolic seed extract of C.pepo var. fastigata was shown at a dose of $400 \mu \mathrm{g} / \mathrm{ml}$ is $78 \%$ by $\mathrm{H}_{2} \mathrm{O}_{2}$ model as shown in Table 3.

\section{Antibacterial activity}

It is evident from the data presented in Table 4 that the sample possesses antibacterial activity. Disk diffusion method showed the resistance of the seed extract to Bacillus subtilis, Escherichia coli, Staphylococcus aureus, and Pseudomonas aeruginosa at a concentration of $50 \mu \mathrm{g} / \mathrm{ml}$ and toward E. coli and P. aeruginosa at a concentration of $75 \mu \mathrm{g} / \mathrm{ml}$, $100 \mu \mathrm{g} / \mathrm{ml}$, and $150 \mu \mathrm{g} / \mathrm{ml}$. It implies that the isolates with a minimum inhibitory concentration at or above or zone diameters at or below the resistant breakpoint are not inhibited by the usually achievable concentration of the agent with normal dosage schedules [36]. As shown in Fig. 1, the largest zones of inhibition were observed in C. pepo seed extract against B. subtilis $75 \mu \mathrm{l} / \mathrm{ml}(14 \mathrm{~mm}), 100 \mu \mathrm{l} / \mathrm{ml}(16 \mathrm{~mm})$, and $150 \mu \mathrm{g} / \mathrm{ml}(19 \mathrm{~mm})$ and $S$. aureus $75 \mu \mathrm{g} / \mathrm{ml}(13 \mathrm{~mm}), 100 \mu \mathrm{g} /$ $\mathrm{ml}(14 \mathrm{~mm})$, and $150 \mu \mathrm{g} / \mathrm{ml}(15 \mathrm{~mm})$. The extract showed high activity against B.subtillus and S. auerus species.

Then, it is evident from the data presented in Table 5 that the sample does not possess antifungal activity. The disc diffusion method result showed the resistance of the C. pepo. seed extract toward both Aspergillus niger and Candida albicans at all the four concentrations. 


\section{DISCUSSION}

Oxidative stress and microbial infections pose a serious health problem around the world \& plants have been an inestimable source of valuable natural products since these are potential source of antioxidants and antimicrobial agents [37]. World Health Organization (WHO) advocates the medicinal plants as the best source of diverse range of drugs and active compounds. Therefore investigations are required in order to explore their properties and understand their safety and efficiency [38]. The present study reports the antioxidant, antibacterial and antifungal activities of methanolic extract of cucurbita pepo seeds. The evaluation of the antioxidant potential was done using $\mathrm{H}_{2} \mathrm{O}_{2}$ and DPPH (qualitative and quantitative methods). Hydroxyl radical formation can occur in several ways by far the most important mechanism in vitro is the fenton reaction where a transition metal involved as a prooxidant in the catalyzed decomposition of superoxide and hydrogen peroxide [27]. Hydroxyl radicals are the most reactive and predominant radical generated endogenously during aerobic metabolism among the ROS which could be formed from superoxide anion and hydrogen peroxide, in the metal ions, such as copper or iron and cause ageing of human and some diseases [28,39]. The hydroxyl radical is an extremely reactive free radical formed in biological systems and has been implicated as a highly damaging species in free radical pathology, capable of damaging almost every molecule found in living cells [30]. Both the results thus established the therapeutic potential against oxidative stress. The reason for the antioxidant activity is the presence of phenolic compounds, tannins and triterpenoids. The antimicrobial screening was performed for B.Subtillis, E.Coli, S.auerus \& P. aeruginosa at a concentration of $50 \mu \mathrm{g} / \mathrm{ml}$ and towards E.Coli \& P. aeruginosa at a concentration of $75 \mu \mathrm{g} / \mathrm{ml}, 100 \mu \mathrm{g} / \mathrm{ml} \& 150 \mu \mathrm{g} / \mathrm{ml}$.. Disk diffusion method showed the resistance of the seed extract in all the samples. The cucurbita pepo var. fastigata seed extract showed high activity against B.subtillus and S. auerus species. The sample do not possesses antifungal activity. However no zone of inhibition against antifungal organism was found hence the disc diffusion method results showed the resistance of the Cucurbita pepo. seed extract towards both A.niger and C.albicans at all the four concentrations. The insight into the inactivity of the extra against A.niger and C.albicans will require further investigation. The growing bacterial resistant towards antibiotics has become a matter of great concern for researchers' worldwide [40]. The antibiotic resistant bacteria have been considered as a major problem by intensive care physicians in the treatment of patients [41]. The increase in bacterial resistant has prompted researchers to explore the antimicrobial role of natural herbs against resistant strains [42, 43]. Many infectious diseases caused by resistant microbes can be treated by seed extracts having potential antimicrobial compounds. The results from our study have shown extremely strong activity in the seed extracts of Cucurbita pepo. Traditionally, herbal medicine is used by folklore for the treatment of various infectious diseases. Although most of the cases are not evaluated scientifically but the chemical constituents of even the simplest medicinal preparations are beneficial [44]. Hence the seed extracts offer an ample potential for the development of novel agents effectual against infections that are presently difficult to treat.

\section{CONCLUSION}

On the basis of the results of the above study, it can be concluded that the methanolic extract of Cucurbita pepo. var. fastigata seeds possess notable antioxidant and antibacterial activity. The Cucurbita pepo var. fastigata seed extract showed high activity against $B$. subtilis and $S$. aureus species, but they have shown no zone of inhibition against antifungal organism which shows that the methanolic extract of seeds does not possess antifungal activity. However, further, investigations are required to comprehend the precise mechanisms of action and isolation of the compound(s) accountable for such activities.

\section{AUTHORS' CONTRIBUTION}

Roshni R.S. Soni - Conceived idea of the study, participated in its design, performed laboratory work and coordinated and helped to draft the manuscript, and also performed statistical analysis. Manoj Bali - Participated in the sequence alignment and drafted the manuscript \& Supervised the study from conceiving of idea to drafting of manuscript.

\section{CONFLICTS OF INTEREST STATEMENT}

We declare that we have no conflicts of interest.

\section{REFERENCES}

1. Vinale F, Sivasithamparam K, Ghisalberti EL, Woo SL, Nigro M, Marra R, et al. Trichoderma secondary metabolites active on plants and fungal pathogens. Open Mycol J 2014;8:127-39.

2. Sofowora A. African Medicinal Plants. IIe-Ife (Nigeria): University of Ife Press; 1984.

3. Sofowora A. Medicinal Plants and Traditional Medicine in Africa. Ibadan (Nigeria): Spectrum Books Ltd.; 1993.

4. McChesney JD, Venkataraman SK, Henri JT. Plant natural products: Back to the future or into extinction? Phytochemistry 2007;68:2015-22.

5. Newman DJ, Cragg GM. Natural products as sources of new drugs over the last 25 years. J Nat Prod 2007;70:461-77.

6. Newman DJ. Natural products as leads to potential drugs: An old process or the new hope for drug discovery? J Med Chem 2008;51:2589-99.

7. Abid R, Mahmood R, Rajesh KP, Swamy BE. Potential in vitro antioxidant and protective effect of cassia fistula linn: Fruit extracts against induced oxidative damage in human erythrocytes. Int $\mathrm{J}$ Pharm Pharm Sci 2014;6:497-505.

8. Dhiman K, Gupta A, Sharma DK, Gill NS, Goyal A. A review on the medicinally important plants of the family Cucurbitaceae. Asian J Clin Nutr 2012;4:16-26.

9. Martha R, Gutierrez P. Review of Cucurbita pepo (Pumpkin) its phytochemistry and pharmacology. Med Chem 2016;6:12-21.

10. Bardaa S, Ben Halima N, Aloui F, Ben Mansour R, Jabeur H, Bouaziz M, et al. Oil from pumpkin (Cucurbita pepo L.) Seeds: Evaluation of its functional properties on wound healing in rats. Lipids Health Dis 2016;15:73.

11. Abdel-Rahman MK. Effect of pumpkin seed (Cucurbita pepo L.) Diets on Benign Prostatic Hyperplasia (BPH ): Chemical and morphometric evaluation in rats. World J Chem 2006;1:33-40.

12. Ratnam N. A review on Cucurbita pepo. Int J Pharmacogn Phytochem Res 2017;9:1190-94

13. Obi RK, Nwanebu FC, Ndubuisi UU, Orji NM. Antibacterial qualities and phytochemical screening of the oils of Curcubita pepo and Brassica nigra. J Med Plants Res 2009;3:429-32.

14. Jafarian A, Zolfaghari B, Parnianifard M. The effects of methanolic, chloroform, and ethylacetate extracts of the Cucurbita pepo L. On the delay type hypersensitivity and antibody production. Res Pharm Sci 2012;7:217-24.

15. Immaculata M, Insanu M, Anne C, Dass S. Development of immunonutrient from pumpkin (Cucurbita moschata Duchense Ex. Lamk.) Seed. Procedia Chem 2014;13:105-11.

16. Sayed H, Seif A. Ameliorative effect of pumpkin oil (Cucurbita pepo L.) against alcohol-induced hepatotoxicity and oxidative stress in albino rats. Beni Suef Univ J Basic Appl Sci 2014;3:178-85

17. Medjakovic S, Hobiger S, Ardjomand-Woelkart K, Bucar F, Jungbauer A. Pumpkin seed extract: Cell growth inhibition of hyperplastic and cancer cells, independent of steroid hormone receptors. Fitoterapia 2016;110:150-6.

18. Salman KS, Ashraf S. Reactive oxygen species: A link between chronic inflammation and cancer. Asia Pac J Mol Biol Biotechnol 2013;21:41-9.

19. Kasote DM, Katyare SS, Hegde MV, Bae H. Significance of antioxidant potential of plants and its relevance to therapeutic applications. Int J Biol Sci 2015;11:982-91.

20. Halliwell B. How to characterize an antioxidant: An update. Biochem Soc Symp 1995;61:73-101.

21. Edeoga HO, Okwu DE, Mbaebie BO. Phytochemical constituents of some Nigerian medicinal plants. Afr J Biotechnol 2005;4:685-88.

22. Harborne JB. Phytochemical Methods a Guide to Modern Techniques of Plant Analysis. $3^{\text {rd }}$ ed. Netherlands: Springer; 1998.

23. Takao T, Kitatani F, Watanabe N, Yagi A, Sakata K. A simple screening method for antioxidants and isolation of several antioxidants produced by marine bacteria from fish and shellfish. Biosci Biotechnol Biochem 1994:58:1780-3.

24. Motlhanka DM. Free radical scavenging activity of selected medicinal plants of Eastern Botswana. Pak J Biol Sci 2008;11:805-8. 
25. Chang MJ, Ho YL, Huang GJ, Lin IH. Study on the antioxidant activities of crude extracts from the roots of Arnebia euchroma and Lithospermum erythrorhizon. Mid Taiwan J Med 2008;13:113-21.

26. Dutra RC, Leite MN, Barbosa NR. Quantification of phenolic constituents and antioxidant activity of Pterodon emarginatus Vogel seeds. Int J Mol Sci 2008;9:606-14.

27. Stohs SJ, Bagchi D. Oxidative mechanisms in the toxicity of metal ions. Free Radic Biol Med 1995;18:321-36.

28. Walling C. Fenton's reagent revisite. Acc Chem Res 1975;8:125-31.

29. Siddhuraju P, Manian S. The antioxidant activity and free radicalscavenging capacity of dietary phenolic extracts from horse gram (Macrotyloma uniflorum (Lam.) Verdc.) Seeds. Food Chem 2007; 105:950-8.

30. Hochstein P, Atallah AS. The nature of oxidants and antioxidant systems in the inhibition of mutation and cancer. Mutat Res 1988;202:363-75.

31. Bauer AW, Kirby WM, Sherris JC, Turck M. Antibiotic susceptibility testing by a standardized single disk method. Am J Clin Pathol 1966;45:493-6.

32. Shad AA, Ahmad S, Ullah R, AbdEl-Salam NM, Fouad H, Rehman NU, et al. Phytochemical and biological activities of four wild medicinal plants. Sci World J 2014;2014:857363.

33. Nyakudya E, Jeong JH, Lee NK, Jeong YS. Platycosides from the roots of Platycodon grandiflorum and their health benefits. Prev Nutr Food Sci 2014;19:59-68

34. Gil MI, Ferreres F, Tomás-Barberán FA. Effect of postharvest storage and processing on the antioxidant constituents (Flavonoids and Vitamin C) of fresh-cut spinach. J Agric Food Chem 1999;47:2213-7.

35. Esmaeili A, Mousavi Z, Shokrollahi M, Shafaghat A. Antioxidant activity and isolation of luteoline from Centaurea behen L. grown in Iran. J Chem 2013;2013:1-5.

36. CLSI. Performance Standards for Antimicrobial Susceptibility Testing. CLSI Supplement M100. Wayne, PA: Clinical and Laboratory Standards Institute; 2017.

37. Singh AR, Bajaj VK, Sekhawat PS, Singh K. Phytochemical estimation and antimicrobial activity of aqueous and methanolic extract of Ocimum sanctum L. J Nat Prod Plant Resour 2013;3:51-8.

38. Mothana RA, Gruenert R, Bednarski PJ, Lindequist U. Evaluation of the in vitro anticancer, antimicrobial and antioxidant activities of some Yemeni plants used in folk medicine. Pharmazie 2009;64:260-8.

39. Siddhuraja $\mathrm{P}$, Becker K. The antioxidant and free radical scavenging activities of processed cowpea (Vigna unguiculata L.) Seed extracts. Food Chem 2007;101:10-9.

40. Gardam MA. Is methicillin-resistant Staphylococcus aureus an emerging community pathogen? A review of the literature. Can J Infect Dis 2000;11:202-11.

41. Lepape A, Monnet DL, participating members, European Society of Intensive Care Medicine. Experience of European intensive care physicians with infections due to antibiotic-resistant bacteria, 2009. Euro Surveill 2009;14:19393.

42. Alviano DS, Alviano CS. Plant extracts: Search for new alternatives to treat microbial diseases. Curr Pharm Biotechnol 2009;10:106-21.

43. Hemaiswarya S, Kruthiventi AK, Doble M. Synergism between natural products and antibiotics against infectious diseases. Phytomedicine 2008; 15:639-52.

44. Barnes J, Anderson LA, Phillipson JD. Herbal Meicine. $3^{\text {rd }}$ ed. London: Pharmaceutical Press; 2007. 